\title{
Best Article Award
}

The Atlantic Economic Journal is proud to announce that the winners of the Best Article Award are Maria Cornachione Kula of Roger Williams University and Daniel L. Millimet of Southern Methodist University. Their paper entitled, "Income Inequality, Taxation, and Growth," appeared in the December 2010 issue of the AEJ. A distinguished committee reviewed all eligible papers published during that year. The committee was chaired by IAES Vice President Alberto Alesina of Harvard University. Members of the committee included the AEJ Board of Editors and IAES Endowment Fund Sponsors. The Managing Editor gratefully acknowledges the participation and diligence of all the intellectual and scholarly approaches to economic research which has always been a focal point of the $A E J$.

The authors analyze the role income distribution plays in the growth process. The political economy argument that inequality is detrimental to growth suggests that greater inequality leads to pressure for redistribution via distortionary taxation, which lowers investment and thus growth. Empirical results are mixed on both the causal link between inequality and growth, and on the intermediate link between inequality and taxation.

Attempts to reconcile this theoretical approach with empirical findings have relied on deviations from the one person, one vote principle, or on credit market imperfections. In this paper, the authors offer a model that neither restricts political participation nor relies on credit constraints, yet is consistent with empirical findings of a longterm negative relationship between inequality and growth, and a possible short-run positive relationship. Furthermore, the model predicts an ambiguous relationship between inequality and redistribution.

The model liberalizes the voting process by allowing multiple referenda. This enables rich agents to act strategically in their consumption (to consume more now to avoid appropriation later) to ensure that the median voter prefers a lower tax rate. This overconsumption, or undersaving, results in lower growth. Thus inequality corresponds to lower growth.

However, the calculations of the rich are correct only in expectation. The model predicts a negative relationship between inequality and growth on average (i.e., in the long run), yet allows for short run positive associations. It also provides an 
explanation for the conflicting findings regarding inequality and taxation, as inequality may lead to low or high taxation, as the strategic actions of the rich are correct only in expectation.

Why might there be income distribution uncertainty? Income inequality originates from an unequal skills distribution. If a "skill-biased technology" shock, which lowers the realized income level of the median voter below its expectation, is unforeseen or underestimated, the model predicts both higher taxes and higher growth compared to the situation of a perfectly forecasted shock. This result is consistent with findings of a negative relationship between inequality and growth in poor countries, but a positive relationship in rich countries, as rich countries are more likely to have experienced a skill-biased technology shock.

John M. Virgo

Managing Editor 